\title{
Complexity is no excuse
}

\section{Introduction of a research model for turning sustainable development from theory into practice}

\author{
Beatrice Hedelin ${ }^{1}[$
}

Received: 18 May 2017 / Accepted: 29 September 2018 / Published online: 16 October 2018

(c) The Author(s) 2018

\begin{abstract}
An overarching research model is introduced here that can support research for turning sustainable development (SD) from theory into practice. The model describes how existing and future theories, and empirical knowledge related to SD can be utilised to establish explicit linkages—steps-between fundamental SD principles and specific studied practices. The research model is intended to support planning, design and communication of a range of research endeavours such as individual studies, larger projects and research programmes. It internalises a number of insights from the current stock of SD literature such as explicitly linking local solutions to general SD principles, the need to embrace complexity and to use theory, the need for interdisciplinarity, and acknowledging SD as both substance and process. The model and its utilisation are explained and illustrated here by reference to a research example from river basin planning. The model is a critical and constructive attempt to establish structure and strategy in relation to the overwhelming complexity of the sustainability challenge-a challenge which urgently calls for reflective and effective research approaches.
\end{abstract}

Keywords Implementation · Research model · Operationalisation · Research design · Sustainable development · Sustainability science

\section{Introduction}

The stock of research engaged with sustainable development (SD) is broad, heterogeneous and steadily growing. Nevertheless, a core of ideas has become well established and widely supported across the different disciplinary fields involved. Three such ideas are: the need for an integrated approach with respect to the three dimensions of ecological, economic and social values; keeping within nature's boundaries; and distributing resources justly amongst people and across generations (Jabareen 2008; Leach et al. 2010; Miller 2013). Other well-established understandings are the

Handled by David J. Abson, Leuphana Universitat Luneburg GERMANY.

Beatrice Hedelin

Beatrice.Hedelin@kau.se

1 Department of Environmental and Life Sciences, Centre for Climate and Safety, Karlstad University, 65188 Karlstad, Sweden importance of adopting a systems' perspective, employing a long-term perspective, integrating scientific disciplines, and involving local actors in the decision-making that concerns them (Jabareen 2008; Jerneck et al. 2011; Lange et al. 2013; Leach et al. 2010; Morse 2008; Robinson 2004; van Kerkhoff 2014).

While this says a lot about the implications of SD in general, theoretical terms, important problems remain. A critical problem, which is central to this study, is that the gap between SD's established core ideas and their specific and practical meanings still remains considerable. Many would argue that such questions are too large to be handled with scientific clarity and rigor. Yet examples of studies that focus on linking SD principles and SD theory to specific practices exist within fields such as adaptive management, ecological economics, integrated approaches to SD, and transition management (see e.g. Ekins et al. 2003; Frame and O'Connor 2011; Grunwald and Rösch 2011; Kopfmuller et al. 2009; Luederitz et al. 2016; Nevens et al. 2013; Rosch et al. 2017). Furthermore, several well-renowned organisations are making important progress in this respect, for example, 
the Harvard Sustainability Science Program, the Centre for Complex Systems in Transition, the STEPS Centre, DRIFT and the Stockholm Resilience Centre.

Typical SD studies, however, still focus on the achievement of a part of the SD concept, and a certain positive development, such as reduced carbon dioxide emission levels, improved working conditions or participation. Sometimes, more than one positive development is included, for example, when asking how hydropower can be produced while minimising the effects on the river ecosystem. The problem here is not that these are not positive developments, but rather that they are related to another well-established understanding here, namely, that the implementation of SD involves complex systems (Jabareen 2008; Leach et al. 2010; van Kerkhoff 2014). Such systems involve numerous factors and feedback loops, and the achievement of one positive outcome affects the possibilities of attaining others (DeFries and Nagendra 2017; Wezemael et al. 2012), for example, the relation between hydropower production and river ecology, and the local economy, the risk of flooding, tourism, and alternative ways of producing energy, etc. Therefore, a fundamental task for SD research is to identify and explain all key factors and their relations, and, to acknowledge all the main inherent value trade-offs (van Kerkhoff 2014). To effectively achieve this, we need to invent new scientific approaches to SD that can deliver the knowledge that society needs to make the decisions and take the actions that steer developments into sustainable paths (Bagheri and Hjorth 2007; Bammer 2015; Leach et al. 2010; Miller et al. 2014; Morse 2008; Sneddon et al. 2006; Wiek et al. 2012). Despite complexity.

The key idea forwarded in this study is that because the gap between SD theory and specific practices is so large and complex, it is not possible to turn theory into practice without constructing a number of explicit steps. These steps help us to handle complexity and necessary simplifications with scientific clarity and rigor, in systematic and reflexive ways.

In what follows, a research model for turning SD from theory into practice is introduced. The model describes the establishment of explicit linkages—steps-between a comprehensive collection of fundamental and well-established principles of SD and specific studied practices. The steps are developed by an iterative procedure of alternation and dialogue between SD principles and practice. The intention is to provide structural and conceptual support for planning, design and communication of a range of research endeavours within the evolving discipline of sustainability science; from research programmes, strategies and larger projects to individual studies. The model can also support reviews of current SD research in various fields. Are important factors neglected? Do the utilised theories provide the support needed to grasp the complexity of the problem studied?
The model is hereafter referred to as STEP (the Sustainable development from Theory into Practice research model).

STEP shares many of the fundamental ideas of the promising approaches to transform SD from theory to practice that currently do exist within the fields and organisations exemplified above, such as the idea of complexity of social ecological systems (e.g. adaptive management and resilience studies), of the need for integration (e.g. the field of integrated approaches to SD), and of transdisciplinary research (e.g. transition management). However, compared to these existing approaches, STEP is an overarching research model. STEP is not an SD theory as such that is to be transformed into practice, but merely an overarching model for SD research that describes how existing and future theories, and empirical evidence collected from various fields and disciplines can be utilised and transformed, including the interaction between theoretical and practical kinds of knowledge during that process. ${ }^{1}$ STEP focuses on SD research as such. As will be further explained through this introductory paper, STEP intends to, simultaneously, provide support for the following key lessons from the last decades of SD research:

- Effective strategies for turning SD into practice need to embrace complexity, and utilise theory

- Disciplinary research provides necessary but insufficient knowledge and perspectives for turning SD into practice. Interdisciplinary research approaches are required

- SD research involves two fundamental perspectives of SD: as system and as process

- SD can be defined in both general and specific terms. Specific definitions are dependent on the knowledge and values of those affected. To not lose sight of fundamental SD principles while defining SD in specific terms, the establishment of explicit links-steps-between general and specific definitions of SD is vital part of a process for turning SD into practice

To illustrate STEP and show a general way of applying it, a research case will be presented using four generic research steps: map, gap, design and contribute. The case example serves to include concretization to the presentation, while the four research steps represent a general way of applying

\footnotetext{
${ }^{1}$ For example, knowledge of social-ecological systems gained in the field of resilience and disciplines such as political science and ecology would be needed to establish various 'steps' in between SD principles and practice, experiences from transition management would be needed to support the process of interaction between theoretical kinds of knowledge and local stakeholder knowledge, and furthermore, knowledge of tools such as indicators and integrated assessment developed by research of integrated approaches to SD would be needed to establish 'steps' for practical implementation.
} 
STEP that can be used, for example, to plan for a research application or a $\mathrm{PhD}$ project. ${ }^{2}$

STEP stems from my own attempts during the last 15 years, in the context of river basin planning, to handle the SD theory-practice gap. ${ }^{3}$ Because STEP's formulation is general, the intention here is to explain the model to the wider SD research community. Application of the model to a range of other contexts and research endeavours will provide knowledge and experience for developing, specifying and refining the model further, and for discussing its usefulness in relation to different types of SD problems.

A background section follows next with the purpose of embedding STEP more broadly in the SD literature. After this, STEP is outlined. Utilisation of STEP is then illustrated by a research case of river basin planning. Last, STEP is discussed in relation to a number of key insights derived from current SD literature as outlined in the background section.

\section{Background: insights from past and current developments of SD}

This short outline of the extensive SD field focuses on what can be learned in relation to the issue of converting SD from theory into practice.

Several authors have described the historical and more recent developments related to SD (recommended overviews are: Ekins 1993; Leach et al. 2010; Mebratu 1998; Miller 2013; Pezzoli 1997; Robinson 2004; Sneddon et al. 2006). Mebratu's (1998) historical description centres on our understanding of the relationship between humans and nature, and goes all the way back to 10,000 years ago when we lived as nomadic hunters and gatherers. Before the industrial revolution, our thinking about the relationship between humans and nature was basically religious in nature, and the traditional wisdom of living in harmony with nature remains one of the cornerstones of the SD concept (Mebratu 1998). It was not, however, until the 1980s that the

\footnotetext{
${ }^{2}$ Various research methods are needed to carry out these four generic research steps. While the issue of methods is highly related to STEP, this introductory paper focuses on the idea of STEP as an overarching model and support for SD research.

${ }^{3}$ I developed the main idea of STEP during the finalisation of my $\mathrm{PhD}$ thesis as I wanted to explain the overarching research approach to SD of my various individual studies. Since completing my PhD in 2008 , the idea has been constantly present. I have been testing and developing it by reflection, and have discussed it with colleagues in other fields. I have also found that there are a number of key problems and insights discussed in the wider SD literature that resemble those I have experienced and attempted to handle by STEP. Through this introductory paper I wish to open up the idea of STEP for wider examination and further development. STEP should be regarded a skeleton and forthcoming work needs to be a collaborative project.
}

term SD became widely used, primarily as a consequence of the UN-sponsored World Commission on Environment and Development led by Gro Harlem Brundtland, and the publication of Our Common Future in 1987 (Sneddon et al. 2006). The definition of SD in the Brundtland report ${ }^{4}$ is still the one most cited (WCED 1987). After the WCED-which was the major political turning point that turned the concept into something of a catch phrase - the debates over SD were both vibrant and intense during the 1990s (Leach et al. 2010; Mebratu 1998). These debates, and the UN Conference on Environment and Development in 1992 (the Rio Conference), did also succeed in shifting the focus of debate from one of defining and understanding SD to turning it into practice (Leach et al. 2010; Mebratu 1998). From this followed the development of a large and still growing number of management tools, such as sustainability frameworks, indicators, and audit and benchmarking systems, which were designed to help governments, businesses, municipalities and individuals make sustainability a reality (Leach et al. 2010). It is, however, difficult to find clear evidence of the substantive effect of these efforts, especially if one looks at the still ongoing trends of environmental degradation, resource depletion and risks, such as climate change, water scarcity, and GMOs (Rockström et al. 2009). Moreover, a variety of critiques emerged pointing out that these efforts fundamentally involve the support of "business as usual"type behaviour, that they are not sufficiently theory based and that they are based on a simplified understanding of the capacity of knowledge and statistics to support sustainable decision-making and societal transition (Jordan 2008; Leach et al. 2010; Robinson 2004; Wiek et al. 2012). From these developments, it has become clear that effective strategies for turning $S D$ into practice need to embrace complexity and utilise theory.

Scientific developments associated with SD began in the field of economics with the development of the theory of limits to growth and environmental limits which was propounded already by Thomas Robert Malthus (1766-1843; Mebratu 1998). Subsequent theories of SD in this field have been developed involving definitions of both weak and strong sustainability, and discussions of the possibility of global economic systems and the ability of the market economy to internalise external costs in policy and decisionmaking $^{5}$ (Ekins 1993; Karlsson 2005; Leach et al. 2010; Mebratu 1998; Rao 1999). In parallel with developments in the economics field, ecologists have long studied how resource extraction and pollution affect ecological systems,

\footnotetext{
${ }^{4}$ It describes SD as meeting "the needs of the present, without compromising the ability of future generations to meet their own needs".

5 Different perspectives related to this issue are offered by the neoclassical and political economy strands of economics.
} 
and from this, the discipline of mathematical ecology blossomed during the 1980s (Leach et al. 2010). From an ecological perspective, sustainability could thus be defined in terms of the ability of ecological systems to withstand the stresses and shocks caused by human activity-the stability and resilience of ecological systems; see Scheffer et al. (2001) for an excellent example.

From the side of political sciences, the literature covering the two concepts 'SD' and 'governance' has grown steadily over the last two decades. It analyses different modes of governance and their compatibility with SD. Dryzek (2013), Dobson (2007) and Eckersly (2004) are well-known exponents of such approaches in the literature, while Kemp et al. (2005) and Jordan (2008) provide useful overviews. One important observation made here (and linked to the critiques against the management tools described above) is that there is clearly a need to develop integrated theoretical frameworks for SD governance rather than simply continuing to apply existing and compartmental theories from the wider field of governance theory (Jordan 2008).

Over time, the arguments for and progress attributable to the use of interdisciplinary approaches to SD have become more evident while interdisciplinary fields such as ecological economics, sustainability science and transition management continue to evolve (Jerneck et al. 2011; Lange et al. 2013; Miller 2013). In spite of this trend, several different standpoints continue to influence definitions of SD. The main standpoints are: the anthropocentric-eco-centric, weak-strong, thin-deep, neoclassical-political economy, and the universalist-procedural and the pragmatic-value changes (for overviews, see Karlsson 2005; Leach et al. 2010; Mebratu 1998; Miller 2013; Pezzoli 1997; Robinson 2004; Söderbaum 2008). These different understandings are often dependent, more or less, on the academic traditions of their followers (Karlsson 2005; Robinson 2004). While many of these can be seen as complementary, others cannot, and the concept must, therefore, still be understood as theoretically contested. Furthermore, a recent review of the vast field of SD shows that few definitions are actually based on interdisciplinary work (Schoolman et al. 2012). So, based on the past decade's academic developments it is clear that disciplinary research provides necessary but insufficient knowledge and perspectives for turning SD into practice. Interdisciplinary research approaches are required as a complement.

Within academia, different approaches have been taken to the operationalisation of SD. Miller (2013), who has undertaken a substantial review of the leading SD journals over the last decade as well as conducting numerous interviews with leading SD researchers, identifies two fundamentally different approaches-the 'knowledge-first approach', and the 'process-oriented approach'. The knowledge-first approach is rooted in the so-called 'universalist' view of SD. In this approach, scientists agree on and are engaged by universal definitions of SD such as the Brundtland definition, which are characterised by a high level of generality and by values that all can agree on. The followers of the knowledge-first approach focus on producing knowledge about the complex dynamics of, and interactions between, human and natural systems. The role of the scientist here is to develop and deliver (objective) knowledge so that the decision-makers can make sustainable decisions. The researchers deliver objective knowledge about the complex socio-ecological systems and the decision-makers handle the value trade-offs connected to societal development. Numerous examples of this approach can be found in research on resilience and adaptive management, ecosystem services, integrated approaches to SD and governance. For typical examples, see e.g. Rockström et al. (2009), Carpenter et al. (2009), Rosch et al. (2017) and Genus (2014).

In contrast, Miller (2013) identifies the process-oriented approach, which is rooted in a procedural view of SD. By this approach, SD is a political and democratic process with learning as a central component. Research here centres on how sustainability comes to be defined and on how it can be realised rather than on the substantial definition of SD. As such, according to the process-oriented approach, SD can only be constructively defined in relation to a certain local context, since the definition depends on the knowledge and values of those who are connected to that context. The role of the researcher here is more active than in the knowledge-first approach in the sense that the researcher produces knowledge about methodologies and processes for, or even participates in, transition towards sustainability. Examples of this approach can be found in fields of social intervention and action research but transition management might be the most clearly committed field, see for example Rotmans and Loorbach (2009), Loorbach and Rotmans (2010) and Nevens et al. (2013). Collaborative or participatory research designs are often used, where the scientists intervene within the study subject. See Lang et al. (2012) for an overview of the state and challenges of such research designs.

From Miller's review (2013), it is clear that $S D$ research involves two fundamental perspectives of $S D$ as system and as process (see also e.g. Bagheri and Hjorth 2007; Robinson 2004). It also follows that $S D$ can be defined in both general and specific terms, and, that specific definitions of SD on the local scale are dependent on the knowledge and values of those directly and indirectly connected to that locality (see also Kemp et al. 2005; Morse 2008). Furthermore, the establishment of explicit links between general and specific definitions of SD is vital part of a process for turning SD into practice (Chesson 2013; Davidson and Venning 2011).

After the presentation of STEP in the following section and the case example, we will return to the insights highlighted here for the purpose of initiating a discussion of how STEP responds to them. 


\section{STEP}

SD research is pursued within a range of scientific disciplines and fields. A deliberate effort has, therefore, been made here to carefully select common model concepts, for the sake of explaining STEP for a wide audience. The STEP research model includes the following concepts, which constitute its building blocks:

- Sustainable development (SD) principles

- Practice

- Sustainable development (SD) framework

- Theory-based approach

- Practice-based approach

In short, $S D$ principles form the theoretical and normative frame for SD research endeavours. Practice is the area of application - the issue in which the research aims to promote sustainability. $S D$ frameworks are structured knowledge of varying levels of specification and detail-the steps that link theory and practice. An SD framework can be developed or utilised in a study by a theory-based approach, which uses a theoretical basis for its study design, or by a practice-based approach, which builds on empirics.

These concepts are defined, explained and related to each other in the following step-wise elaboration of the model and the model illustration (Figs. 1, 2, 3).

\section{SD principles}

A basic feature of STEP is the use of SD principles as a theoretical and normative frame for SD research. A sustainability principle (SD principle) is defined here as a fundamental component of SD which is well established within the scientific literature. Even if definitions and perspectives in respect of SD vary, it is possible to identify and formulate a number of such principles associated with SD. In a literature review (Hedelin 2008b), ${ }^{6}$ seven SD principles that are generally adopted have been identified. These principles are described

\footnotetext{
6 The literature review is based on searches of Web of Science between the years 2005 and 2008 (c.f. Cooper 1998; Fink 2005). The search terms 'sustainable development', 'theory', 'concept' and 'principle' were used in different combinations (mainly in the title field). References of the included papers, and papers that cite included papers, were also included (using the Relater Records function in Web of Science). Assessment of the paper's relevance for the question "what, at a fundamental level, does SD imply?" was used as basis for selection and for reviewing their content. The selected papers included studies with a theoretical, generic perspective on SD, but also papers on SD from the fields of river basin management and planning. The review was completed when no relevant content outside of the derived categories were found after continued reviews of a large number of additional papers.
}

using different wordings in literature but grouped into seven distinct principles (Table 1).

Reference to these SD principles is a way of explaining SD in general terms, as illustrated in Fig. 1. The SD principles may, however, have different relevance and importance in relation to a specific studied practice. A first step when applying STEP is, therefore, to carefully assess the practice at hand in relation to the set of SD principles, and select those SD principles which are of greatest relevance and importance. Principle selection is generally necessary both for reasons of systematic simplification and of relevance. In cases where all principles are assessed to be equally or almost equally important, all principles need to be included, because a sustainable practice cannot counteract any relevant SD principle. Such a comprehensive approach would require extensive research and a large number of related studies.

The selection of principles is a fundamental choice because it steers both the theoretical and normative premise of the research. Principle selection should be based on what is currently known about the type of practice at hand. It can be based, e.g., on a broad literature review or on interviews with a broad group of researchers. The disciplinary backgrounds of the persons that make the selection of SD principles for a particular practice will influence the assessment. Therefore, a prerequisite here is that a broad interdisciplinary and critical research perspective is applied. Based on an initial review, it might not be obvious which are the most relevant principles in relation to the practice at hand. Therefore, the selection of principles must be iteratively reassessed during the course of a research process.

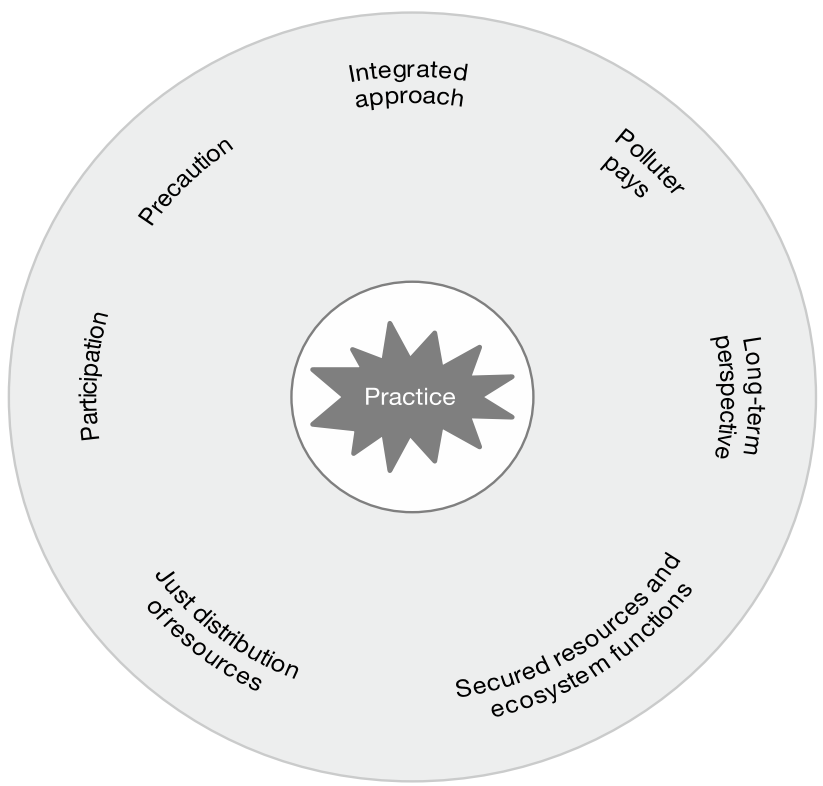

Fig. 1 Well-established SD principles constitute the theoretical and normative frame for the research. Practice is the area of application of SD 


\section{Practice}

Practice is defined here as the area of application of SD. In other words, the issue for which one wants to turn SD from theory into practical activities, solutions or decisions. Examples of practices are: river basin planning, energy system policy, environmental technology, transportation systems, chemical substances law and an institutional system for environmental governance.

\section{SD frameworks}

The gap between general definitions of SD and ways of defining SD that apply to a specific practice is considerable, and without one or several steps in between there is an obvious risk of losing track of the SD principles during the process of explaining and defining SD in detail. To support the systematic establishment of such guiding steps between SD principles and practice, STEP includes SD frameworks. An SD framework is a structure of systematised knowledge that explicitly describes, in greater detail than the SD principles themselves, what the selected SD principles imply for a certain practice. See Fig. 2.

The SD framework can be characterised by its level of detail. With low levels of detail the character of the SD framework is theoretical. This kind of SD framework is illustrated by the larger inner circle. For more applied research, an SD framework of a more specific, detailed, character is useful, illustrated by the smaller inner circles. Such a detailed SD framework is more context dependent, so as the

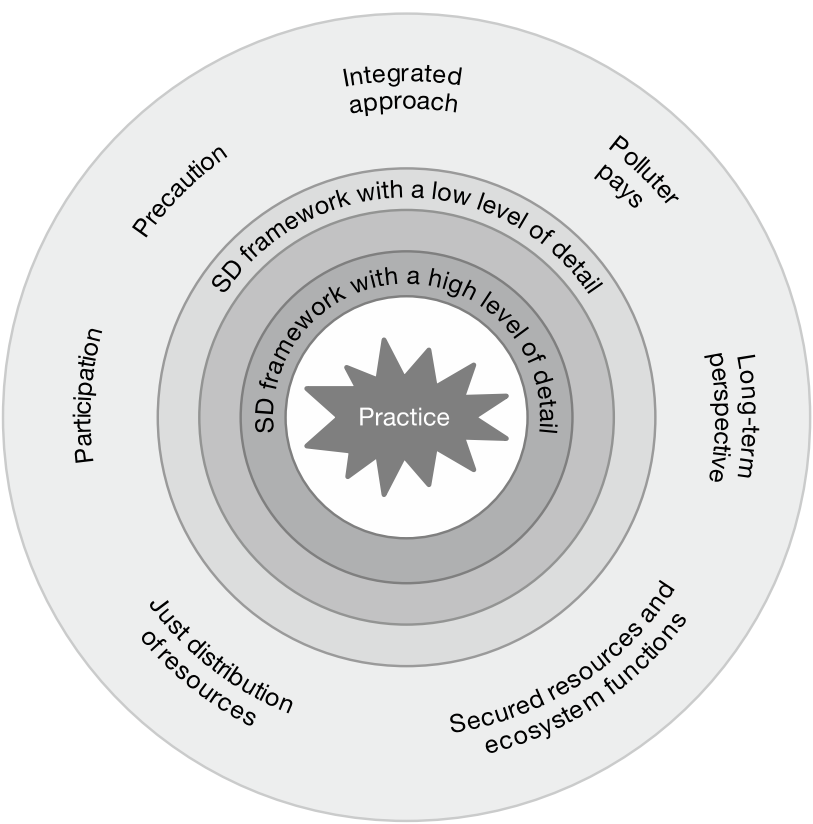

Fig. 2 SD frameworks of varying levels of detail establish explicit links-steps-between the SD principles and the studied practice. The SD frameworks are illustrated as circles level of detail of the SD framework increases, the practice it applies to becomes more specified and delimited. This is illustrated by the decreasing circle size.

\section{Theory-based and practice-based approaches}

Figure 3 provides a complete illustration of STEP, including its last two concepts. A theory-based approach is when the most relevant SD principles are used as a basis for deductively deriving an SD framework with more specificity than the principles. The framework defines SD for a certain practice, and it can be used as theoretical basis for deductive research aimed at delivering an understanding of, and developing, that practice. To continue the research process with a theory-based approach, a new SD framework with a higher level of detail than the first framework would be derived based on the previous SD framework.

The practice-based approach uses empirical knowledge to develop an SD framework. This is an important complement to theory-based approaches, especially when it comes to the establishment of SD frameworks with a high level of detail. Such empirical studies of inductive design can also be used to analyse and to assess existing SD frameworks: Does the SD framework capture the main aspects of the practice that it is targeting? If important aspects are missing, this could indicate that the SD framework may not include the most relevant SD principles in relation to the studied practice, and a need for further theory and/or framework development.

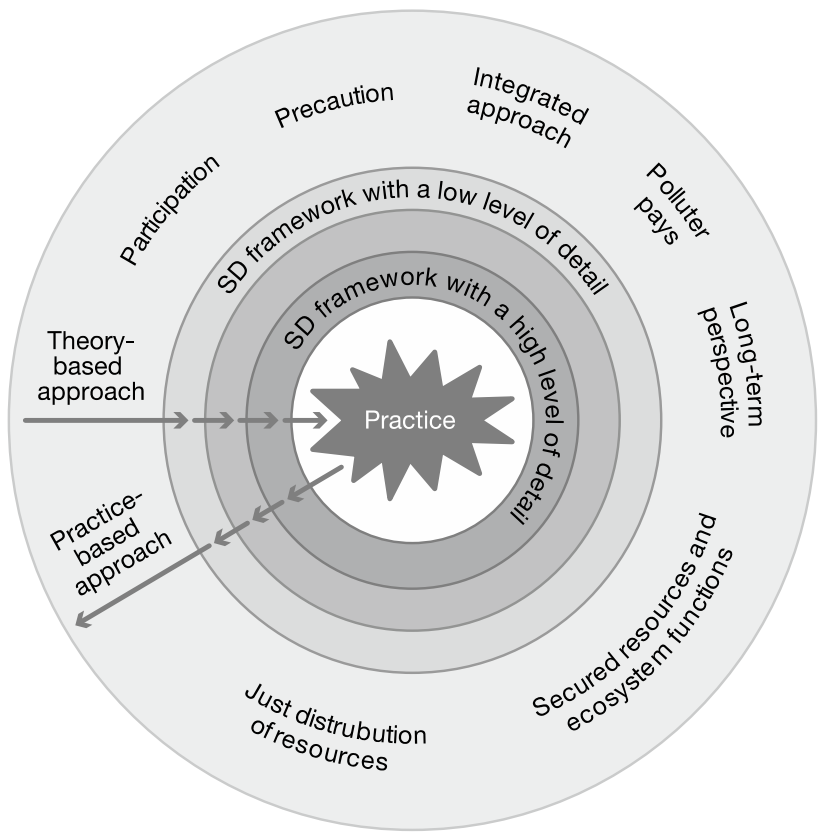

Fig. 3 Research approaches can be theory based (deductive) or practice based (inductive), or can include both. The figure outlines the complete STEP research model 
Table 1 Outline of SD principles

\begin{tabular}{|c|c|}
\hline Principles & Examples of references \\
\hline \multicolumn{2}{|l|}{ Secured resources and ecosystem functions } \\
\hline $\begin{array}{l}\text { Humans' and other species' life and wellbeing depend on the earth's resources and system functions. } \\
\text { SD implies that critical resources and system functions cannot be depleted or disrupted in ways that } \\
\text { threatens our lives and wellbeing }\end{array}$ & $\begin{array}{l}\text { Costanza et al. (2000), Folke (2006), } \\
\text { Holling (2001), Rockström et al. } \\
\text { (2009), Steffen et al. (2015) }\end{array}$ \\
\hline \multicolumn{2}{|l|}{ Just distribution of resources } \\
\hline $\begin{array}{l}\text { SD entails a just distribution of resources among the species and people living on the planet today } \\
\text { and between present and future generations, so that their basic needs are met and their quality of } \\
\text { life is secured }\end{array}$ & $\begin{array}{l}\text { Daly (1990), Costanza et al. (2000), } \\
\text { Meisch (2016), Walker }(2009,2012)\end{array}$ \\
\hline \multicolumn{2}{|l|}{ Participation } \\
\hline $\begin{array}{l}\text { Understanding and definition of SD for a certain issue or locality depend on the knowledge and val- } \\
\text { ues of those directly and indirectly connected to that issue or locality. Participation is also a prereq- } \\
\text { uisite for implementation of SD decisions. Participation must be guided by democratic principles }\end{array}$ & $\begin{array}{l}\text { Dryzek (2013), Hemmati et al. (2002), } \\
\text { Kemp et al. (2005), Lane (2003), } \\
\text { Morse (2008), Wagner et al. (2002) }\end{array}$ \\
\hline \multicolumn{2}{|l|}{ Integrated approach } \\
\hline $\begin{array}{l}\text { SD strategies need to be based on an integrated approach, e.g. with respect of geographical scales, } \\
\text { timescales, societal sectors, actors, values and disciplines. An integrated approach entails having all } \\
\text { relevant factors and their linkages in view while also identifying and focusing on the key aspects of } \\
\text { the problem, selectively targeting the critical issues }\end{array}$ & $\begin{array}{l}\text { Bellamy et al. (1999), Born and Son- } \\
\text { zogni (1995), Frame and O'Connor } \\
\text { (2011), Jepson (2001), McMichael } \\
\text { et al. (2003), van Kerkhoff (2014) }\end{array}$ \\
\hline \multicolumn{2}{|l|}{ Long-term perspective } \\
\hline $\begin{array}{l}\text { Activities such as emissions and resource use by today's generation can affect future generations, } \\
\text { and, processes of societal change for SD are often slow. Therefore, a strategic, long-term approach } \\
\text { is a prerequisite of SD }\end{array}$ & $\begin{array}{l}\text { Costanza et al. (2000), Leach et al. } \\
\text { (2010), Meuleman and Veld (2010) }\end{array}$ \\
\hline \multicolumn{2}{|l|}{ Precaution } \\
\hline $\begin{array}{l}\text { Decision-making for SD involves uncertainties and risks. The precautionary principle does not imply } \\
\text { that all risks should be avoided, but that a cautious approach to risk is applied that involves avail- } \\
\text { able knowledge, key uncertainties and values }\end{array}$ & $\begin{array}{l}\text { DeFries and Nagendra (2017), } \\
\text { O’Riordan and Jordan (1995), Renn } \\
\text { (2009) }\end{array}$ \\
\hline \multicolumn{2}{|l|}{ Polluter pays } \\
\hline $\begin{array}{l}\text { This principle holds that those who generate pollution and waste should bear the costs of contain- } \\
\text { ment, avoidance and abatement }\end{array}$ & $\begin{array}{l}\text { Karlsson (2005), Preston (2009), de } \\
\text { Sadeleer (2002) }\end{array}$ \\
\hline
\end{tabular}

The principles have been identified by a literature review (Hedelin 2008b) (see footnote 4) (the table has been supplemented with newer references and adjusted to the wise comments of the anonymous reviewers)

Both theory-based and practice-based research approaches, and combinations of these, can be used to develop an SD framework. When it comes to developing a specific practice, however, as in a research and development project, the use of transdisciplinary ${ }^{7}$ research designs is often needed. Such studies combine theory-based and practice-based approaches, and allow theoretical and contextual knowledge to interact directly in a dynamic but structured research process revolving around the SD framework.

\section{Illustration of STEP: the case of sustainable river basin planning}

The case example illustrates STEP and shows how it can support research that explicitly links SD theory to specific practices. The example is taken from my own

\footnotetext{
7 A transdisciplinary research approach addresses societal problems through interdisciplinary research as well as collaboration between researchers and other actors. Its aim is to enable mutual learning processes between science and society (Jahn et al. 2012; Lang et al. 2012).
}

research and includes several individual studies on water and flood risk planning over the last 10 years which centre on sustainable planning procedures in Sweden and EU (Hedelin 2007, 2008a, b, 2015a, b, 2016; Hedelin and Lindh 2008).

The case is structured by four basic research steps, such as map, gap, design and contribute, which are explained in generic terms before each step is illustrated. These research steps illustrate a general way of applying STEP, which can be used, for example, to plan for a research application or a $\mathrm{PhD}$ project. Various specific research methods are needed to carry out these steps. ${ }^{8}$ For a full account of the specific methods used in the studies that make up the case example, see (ibid.).

\footnotetext{
8 The issue of methods is much related to STEP. This introductory paper, however, focuses on the idea of STEP as an overarching model for SD research. See the discussion for some further points on, and examples of, methods.
} 


\section{Map}

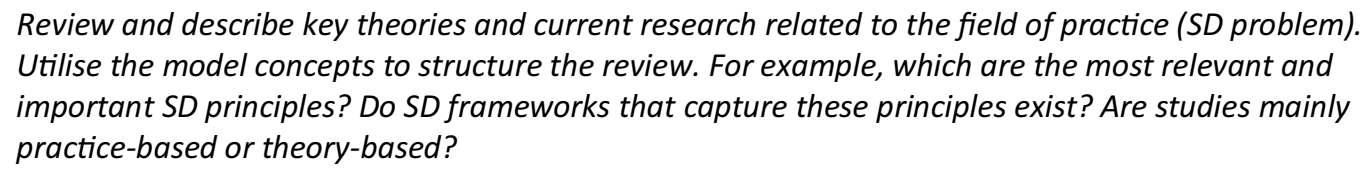

The studied field of practice is the related fields of water resources and flood risk planning. Sweden and EU, which are studied in particular, are heavily influenced by the EU Water Framework Directive (WFD; EU 2000) and the EU Floods Directive (FD; EU 2007). This extensive legislation aims to achieve sustainable management in relation to water and flood risk issues. For the sake of creating a more integrated planning system, they prescribe the use of river basins as administrative units. Both directives also point to the need to engage the stakeholders affected by the decisions to be made.

Participatory and collaborative planning approaches are highlighted as key by both researchers and practitioners, and various kinds of stakeholder-based activities are being developed, practised and studied (e.g. Ananda and Proctor 2013; Koehler and Koontz 2008). One of the main targets of these studies is to formulate the keys to promoting successful practice, see, for example, Vári (2004), and Leach and Pelkey (2001). Participation can, therefore, be considered a main $S D$ principle in this field.

Another SD principle that is broadly recognized both in water resources and flood risk planning research is Integration (e.g. Adam-Bradford 2009; Vinet 2008).

No theoretical framework that explicitly and comprehensively relate to key SD principles exists in the field.

Practice-based studies dominate the field, and typical study objects are groups of stakeholders taking part, or even taking the lead, in local water management. These groups are typically asked to explain their main achievements and the factors that determined success or failure. This research has established an important knowledge base for these kinds of participatory approaches.

Table 2 provides and overview of the case.

\section{Gap}

authorities (Hovik and Hanssen 2016; Lundqvist 2004). Implementation has resulted in a highly fragmented and complex water governance system. In Sweden, the directives have led to the establishment of new administrative systems for river basins, and the formation of over 100 water councilsstakeholder groups of municipalities, farmers, river regulators, industries, fishing associations, environmental organisations, etc. But the fundamental participatory intentions have yet been difficult to operationalise (Jager et al. 2016).

Research on participatory planning in the water field clearly relates to the $S D$ principle of Participation, but it generally lacks explicit and systematic engagement with the SD principle of Integration. Several relevant theories of different levels of detail do exist, however, in relation to both of these key SD principles. These can be found within disciplines and fields such as political science, human geography, psychology, sociology, public administration, multi-level governance, participatory planning and deliberative democracy. No theory or theoretical framework alone, however, captures the range of key aspects connected to participatory water and flood risk planning.

This basic lacuna raises several problems. A main part is related to the fact that participatory approaches are seldom studied in relation to their organisational, political and geographical contexts in this field. For example, are all actors that are indirectly and directly concerned with the issue represented in the stakeholder group? How do persons outside the group assess the function of the group? Do the definitions of success and failure differ between the group members and persons outside of the group? What formal mandate does the group have? What potential democratic problems are related to the participatory planning process? What power issues are involved? This calls for complementary theory-based approaches that make use of theory, and, basing research design on a widened scope of principles.

Identify - based on the map - important gaps. For example, is there a gap in theory support (steps) between the identified SD principles and studies of practice? Are any key aspects or principles neglected? What key knowledge is lacking? Are research approaches lacking?

In Sweden and the EU, the implementation of the WFD and the FD into member states' planning systems has proven difficult, due to problems associated with coordination between legislations, democratic models, policy fields, and interacting
As explained above, practice-based studies dominate the field. Therefore, another gap is the lack of studies using comprehensive theory-based approaches. 
Table 2 Overview of the illustrating case

\begin{tabular}{|c|c|c|c|c|}
\hline \multirow{2}{*}{$\begin{array}{l}\text { STEP con- } \\
\text { cepts }\end{array}$} & \multicolumn{4}{|l|}{ Research steps } \\
\hline & Map & Gap & Design & Contribute \\
\hline Practice & $\begin{array}{l}\text { Water planning. Specifi- } \\
\text { cally, practices in Sweden } \\
\text { and EU }\end{array}$ & $\begin{array}{l}\text { Knowledge of participatory plan- } \\
\text { ning in complex governance } \\
\text { settings is lacking }\end{array}$ & $\begin{array}{l}\text { For water planning as such } \\
\text { and for practices in Sweden } \\
\text { and EU }\end{array}$ & $\begin{array}{l}\text { Assessed practices in EU and } \\
\text { Sweden including practica- } \\
\text { ble advice }\end{array}$ \\
\hline $\begin{array}{l}\text { SD princi- } \\
\text { ples }\end{array}$ & $\begin{array}{l}\text { The principles of participa- } \\
\text { tion and integration are the } \\
\text { most referenced }\end{array}$ & $\begin{array}{l}\text { Knowledge related to par- } \\
\text { ticipation and integration is not } \\
\text { integrated }\end{array}$ & $\begin{array}{l}\text { Integration of participation } \\
\text { and integration }\end{array}$ & - \\
\hline $\begin{array}{l}\text { SD frame- } \\
\text { work }\end{array}$ & Not identified & $\begin{array}{l}\text { Theory support that integrates } \\
\text { key SD principles is lacking }\end{array}$ & $\begin{array}{l}\text { Establishment of a SD frame- } \\
\text { work based on participation } \\
\text { and integration }\end{array}$ & $\begin{array}{l}\text { A SD framework based on } \\
\text { Participation and Integra- } \\
\text { tion is developed-the SPF }\end{array}$ \\
\hline $\begin{array}{l}\text { Research } \\
\text { approach }\end{array}$ & $\begin{array}{l}\text { Practice-based studies } \\
\text { dominate }\end{array}$ & Theory-based studies are lacking & $\begin{array}{l}\text { Theory-based designs, both to } \\
\text { establish the SD framework } \\
\text { and to assess practice }\end{array}$ & - \\
\hline
\end{tabular}

The STEP concepts support structuring the case research explicitly to the main principles of sustainable development. The research steps is a general way of applying STEP

\section{Design}

Design your research programme, study or application based on the gaps and on STEP's structure and concepts. For example, if you have found that there is a lack of an SD framework, design a study or research programme for that purpose.

To widen the scope of principles and to develop a theorybased research approach, extensive work was undertaken in relation to the establishment of an $S D$ framework for river basin planning, based on the two $S D$ principles participation and integration. The SD framework is established using a mainly theory-based approach. It is derived from an extensive review and synthesis ${ }^{9}$ of the theoretical and empirical literatures dealing with the implications of integration and participation in relation to planning procedures. Later, the framework had been further developed by interviews with senior researchers in the field. The scope of the scientific
In several water planning studies in Sweden and of the WFD as such, the SD framework has been used as a theoretical basis for studying water and flood risk planning practices by means of a theory-based approach. Semi-structured interviews and legislative text have mainly been used as sources of data, which mainly have been examined using structured content analysis.

\section{Contribute}

Describe how the study or research programme will contribute to turning SD from theory into practice.

Contributions can be of both applied and theoretical character.

knowledge relevant for capturing the complexity of the studied problem is considerable. To address this and to allow for a continued reflexive research design, the framework is of a general character. ${ }^{10}$ Another reason for the low level of specification is that the framework is intended to be applicable to a wide range of water and flood risk planning practices.

\footnotetext{
9 The production of a synthesis entails the integration of the relevant areas of the literature into a new whole (Kirkevold 1996). Rather differently from a traditional review, a synthesis claims to present connections that have not previously been made (ibid.).

${ }^{10}$ See van Kerkhoff (2014) for an extended explanation of the need for minimal specifications in research methodologies in sustainability science.
}

The main theoretical contribution of this example is the $S D$ framework, termed the sustainable procedure framework (SPF) for river basin planning. See Table 3 for an outline. For a detailed explanation of the SPF and of how it is derived, see Hedelin (2007, 2015a, 2016).

The criteria that mainly stem from the $S D$ principle Integration are much influenced by research on integrated planning and management (Bellamy et al. 1999; Born and Sonzogni 1995; Margerum 1999; Sneddon et al. 2002) and by research on organisational coordination and collaborative planning (O'Leary and Vij 2012; Prager 2010; Rashman et al. 2009; Susskind et al. 2012; Weiss and Hughes 2005). These criteria are structured based on the idea that 
Table 3 The table outlines the sustainable procedure framework (SPF) for river basin planning

\begin{tabular}{|c|c|c|}
\hline SD principle & Theme & $\begin{array}{l}\text { Criteria } \\
\text { Sustainable river basin planning processes shall include, support or promote ... }\end{array}$ \\
\hline \multirow[t]{9}{*}{ Integration } & \multirow[t]{3}{*}{... across disciplines } & Integration of knowledge from all relevant disciplines \\
\hline & & Handling of different views of knowledge (e.g. positivist, relativist) \\
\hline & & Handling of different kinds of uncertainty \\
\hline & \multirow[t]{2}{*}{....across values } & Identification of the most relevant values in relation to the current issue \\
\hline & & $\begin{array}{l}\text { Rational argumentation based on the identified values, by relating them to alterna- } \\
\text { tive choices in the planning process }\end{array}$ \\
\hline & \multirow[t]{4}{*}{...across organizations } & Organisational learning \\
\hline & & Handling of the formal planning context \\
\hline & & Handling of incentives, including resources and efficiency (removal of thresholds) \\
\hline & & Handling of human aspects coordination (trust, engagement, conflict management) \\
\hline \multirow[t]{7}{*}{ Participation } & \multirow[t]{3}{*}{...contributing to the process } & Inclusion of knowledge owned by relevant actors \\
\hline & & Inclusion of the ideological orientations represented by relevant actors \\
\hline & & Participation in the most critical phase(s) of the process \\
\hline & \multirow{4}{*}{$\begin{array}{l}\text {...generating commitment, legiti- } \\
\text { macy or acceptance }\end{array}$} & A procedure for defining the actors that should be involved \\
\hline & & Handling of power asymmetries \\
\hline & & $\begin{array}{l}\text { Procedures that ensure that ideological orientations are not suppressed (for } \\
\text { consensus-based approaches) }\end{array}$ \\
\hline & & Stakeholder learning \\
\hline
\end{tabular}

It synthetises research from several fields. For a complete description of the SPF and of how it is derived, see Hedelin (2007, 2015a, 2016)

integration can be obtained across disciplines, values and organisations (Jepson 2001). The criteria most closely linked to the $S D$ principle of Participation are much influenced by participatory planning and deliberative democracy (Dryzek 2013; Grote 2002; Healey 1996). The criteria are structured according to the main aims related to participation-increasing the quality of decisions, and generating the necessary commitment, legitimacy or acceptance (Hemmati et al. 2002).

The SPF has been used to provide structured and theorybased analyses of water and flood risk planning practices in Sweden and the EU, explicitly related to the SD concept (theory-based approach). These studies have provided a deeper understanding connected to the WFD and the FD. For example, it has been shown that the implementation of the WFD and the FD is characterised by ambiguous and heavily overlapping mandates, unbalanced administrative and operational powers and democratic deficits (Hammer et al. 2011; Hedelin and Lindh 2008; Hedelin 2015b; Lundqvist 2004). Through the directives, there has been a movement from local representative democratic decisionmaking towards regional expert-based decision-making ((Hedelin and Lindh 2008; Hedelin 2015b). Furthermore, a key problem identified is that the WFD does not support explicit handling of value trade-offs related to water management decisions (Hedelin 2008a). A main reason is that the WFD constructs the definition of objectives as a complicated natural scientific procedure. This has resulted in a situation where trade-offs are overshadowed by questions of data shortage and expertise (Hedelin 2008a; Hedelin and Lindh 2008). (Hedelin and Lindh 2008; Hedelin 2015b).

The studies have also delivered practical advice on how to ensure that the studied practices are better assessed in relation to the two selected SD principles (Hedelin 2008a; Hedelin and Lindh 2008; Hedelin 2015b). One recommendation is to reformulate the environmental objectives of the EU Water Framework Directive to include value trade-offs. A related example is to focus the participatory activities on the issues that steer the outcome of the planning processes the most, namely the formulation of objectives and granting of exceptions. Currently, participatory activities are mainly concerned with prioritising and implementing environmental measures. Another example is to integrate a request for a participation plan in the WFD that explicitly reports on how to handle issues such as power, representation, resources and efficiency.

\section{Discussion}

STEP stems from my own previous work dealing with the blurry and endlessly questioned concept of SD in the field of river basin planning. This section aims to initiate a wider discussion of STEP. It is structured by the following insights 
of converting SD from theory into practice. ${ }^{11}$ Effective strategies need to embrace complexity and utilise theory, to use interdisciplinary knowledge, to acknowledge SD as both system and process, and, to connect general and specific definitions of SD.

\section{Embrace complexity and utilise theory}

Past developments and attempts to turn SD into practice through indicators, audits and benchmarking systems, and simplified understandings of societal transition have taught us that effective strategies for turning SD into practice need to embrace complexity and use theory (Jordan 2008; Leach et al. 2010; Robinson 2004). To explain in specific terms what SD implies for a certain practice is indeed a difficult and extensive task. There are existing important approaches to and examples of connecting general understandings of SD (SD theory) to specific practices. Specifically, frameworks and evaluation criteria for sustainability assessment derived from general definitions of SD have been developed and used successfully for aiding transdisciplinary transition processes (see e.g. Ekins et al. 2003; Frame and O'Connor 2011; Grunwald and Rösch 2011; Kopfmuller et al. 2009; Luederitz et al. 2016; Nevens et al. 2013; Rosch et al. 2017). However, I have not yet found an overarching model for SD research that attempts to span the width of the SD concept and provide a generic structure for relating that explicitly and systematically to practice.

STEP, although simple in its basic form, caters for complexity and theory connection by describing the establishment of interconnected levels of theory in the form of SD frameworks. The intention is to structure synthesised theory and knowledge of key factors and their relations for a certain kind of practice. SD frameworks aim to support systematic studies of complex systems of different kinds, and at different and interconnected levels of specification. Furthermore, using a wide range of fundamental SD principles that are well established in current academic SD literatures as a theoretical baseline, research strategies using the model will be directly or indirectly theory based, and related to the full breadth of SD. Studies using a theory-based approach are directly based on theory, while studies using a practicebased approach are indirectly based on theory because the model holds that such studies need to be combined with theory-based approaches not to lose track of the fundamental SD principles. See the last section here for a discussion of practice-based approaches, and the connection to specific and theoretical definitions of SD.

\footnotetext{
11 These insights are derived from argumentation supported by current SD literature (see the background section).
}

As shown in the case example, the SD principles included in a study steer how practice is understood. Inclusion of too few principles may lead to a too simplified understanding and to wrong conclusions about how a certain practice can be altered or managed. In the case example, one additional principle was included compared to most participatory studies within the water planning field. This extended the theoretical basis and range of analysed factors considerably. It supported a deeper understanding of participatory processes studied in this field, because the SPF (the SD framework of the case) allows studying participatory processes as integrated, rather than isolated, parts of a governance system. It was shown, by broadening the analysis frame, that while the studied water planning processes have strong potential to enhance the water governance system in relation to the participatory principle, it also brought important problems to the system in terms of democracy.

I assessed the two SD principles included in the case example the main relevant SD principles, based on a broad literature review and on interviews with senior researchers. To ensure, however, that a water planning process that meets the current SPF criteria also contributes to, or does not counteract, meeting any of the other SD principles, continued work on the SPF would be necessary. Surely, my own person and background played an important role in selecting and interpreting the literature reviewed and the interviews. To ensure that such kind of bias do not bring important deficits to a SD framework-in other words, to ensure that it does embrace complexity - an assessment of all the SD principles in relation to the studied field of practice is necessary. That requires a large and truly interdisciplinary research approach, which brings us to the next section. The section below that discusses SD as process and SD as system, which is also related to principle selection.

\section{Interdisciplinary knowledge}

Disciplinary research provides necessary but insufficient knowledge and perspectives for turning SD into practice and, therefore, interdisciplinary research approaches are required as a complement (Jerneck et al. 2011; Lange et al. 2013; Miller 2013). True interdisciplinarity, which adopts an integrated perspective rather than multiple complementing disciplinary perspectives, is still rare, however, and difficult to achieve (Bammer 2015; Schoolman et al. 2012).

STEP is no solution to the difficulties connected to interdisciplinarity. Scientific traditions, financial systems and research organisational factors play key roles here. STEP, however, provides an overarching research model that can assemble different disciplinary and interdisciplinary perspectives and approaches to SD research. The key component here is using a comprehensive set of well-established SD principles as the theoretical and normative foundation for 
Table 4 The SD principles are emphasised and studied within various disciplines and fields

\begin{tabular}{ll}
\hline SD principle & $\begin{array}{l}\text { Examples of disciplines and fields } \\
\text { that provide key knowledge for operationalisation }\end{array}$ \\
\hline Secured resources and ecosystem functions & $\begin{array}{l}\text { Ecology, technology, physical resource theory, environ- } \\
\text { mental science, resilience studies }\end{array}$ \\
Just distribution of resources & Economics, development studies, social justice, philosophy \\
Participation & Political science, sociology, planning \\
Integrated approach & Economics, public administration, integrated management \\
Long-term perspective & Planning, economics, futures studies \\
Precaution & Economics, risk assessment, resilience studies \\
Polluter pays & Law, economics, technology \\
\hline
\end{tabular}

all SD research endeavours. The SD principles are emphasised and studied within various disciplines and fields, see Table 4 for examples. The task is to select the pertinent SD principles openly and critically in relation to a field of practice, and this is also a demand for interdisciplinarity. STEP provides a structure for interdisciplinary research designs and processes.

In the illustrating case, the SD framework (SPF), which was based on the SD principles, integration and participation, integrates a number of complementary theoretical perspectives and knowledge, for instance, from philosophy, sociology and political science, such as Habermas's ideas of deliberative democracy, Foucault's ideas of power and Ostrom's work related to governance of common pool resources. The SPF was developed by myself ${ }^{12}$ through an extensive literature review and synthesis and through interviews with researchers. It includes the two SD principles that I have found to be the main relevant principles for water planning processes. A fully fletched research process for establishing an SD framework would, however, require both various disciplinary scholars and those with broader backgrounds to ensure that the produced SD framework is complete and does not suffer from disciplinary biases. It would be useful, in particular for questions of legitimacy, that the disciplinary backgrounds of the researchers involved in producing or applying an SD framework would be accounted for as part of the reported study method.

Knowledge and methods for interdisciplinary research are evolving, and there are good arguments for the need to establish a new methodological discipline for researching complex real-world problems Bammer (2013a, b). Such a discipline would indeed be useful for studies described by STEP, and for developing STEP further. Questions to be addressed include: how can STEP be developed further to

\footnotetext{
${ }^{12}$ My disciplinary background: I have a Master of Science in Surveying (from 2001), specialised in Land and water resources. I have a $\mathrm{PhD}$ (2008) in Environmental and energy systems, where I studied planning and decision-making from a process perspective.
}

support truly interdisciplinary research to a greater extent than currently? Can guidance be developed on the disciplines and fields that can best be mined for knowledge relating to the different SD principles and for different kinds of practices? Can guidance be developed on the research methods which are appropriate for different types of STEP studies, at different levels of theory, and for different types of research questions? For example, approaches to knowledge and theory synthesis are needed to develop SD frameworks. Currently, the most commonly advocated such approach is team science, i.e. collaboration between researchers from various disciplines, and a number of supporting tools for team science are already being used and shared within a growing community, such as the Integration and Implementation Sciences (I2S). One example is prenuptial agreements for scientists (Gadlin and Jessar 2002), which are a list of questions for scientific collaborators that helps identifybefore collaborating — core issues such as authorship, adding additional collaborators, and identification of who does what in the collaboration. Another example is the eight-question framework for scoping (Bammer 2013a, b), which is a structured way for a group of researchers to review all the possibilities for understanding and acting on a complex problem. A complete list of tools for interdisciplinary research would be long, but still—which new methods need to be developed, e.g. for systematic establishment of SD frameworks?

\section{SD as system and process}

From Miller's review (2013), it is clear that SD research involves two fundamental perspectives: SD as system and as process (see also e.g. Bagheri and Hjorth 2007; Robinson 2004). In the main, research applying the first perspective focuses on developing knowledge and understanding of complex socio-ecological systems, see e.g. Holling (2001), Rockström et al. (2009), Carpenter et al. (2009) and Genus (2014). The other perspective is focused on processes of societal transition towards SD, see e.g. Rotmans and Loorbach (2009), Loorbach and Rotmans (2010) and Nevens et al. (2013). 
STEP is based on the view that both perspectives are necessary for turning SD from theory into practice. To apply this, STEP includes SD principles of both substantive and processual characters. Two of the principles-'Secured resources and ecosystem functions' and 'Just distribution of resources' - describe sustainable socio-ecological systems in terms of substance. The other principles merely describe $\mathrm{SD}$ as an approach, or process. When selecting the main SD principles of a research endeavour, it may help to think of the practice at hand in terms of substance or process, since the principles of one character can be expected to be more relevant for practices of the same character. So, when studying SD in relation to a current or potential future state of a socio-ecological system, the substance principles would be an obvious selection, while the other principles will be more relevant for studies of the planning and decision-making processes that had brought us, or will potentially bring us, to that state. The illustrating case concerns river basin planning processes, why the principles of process character are the most obvious selection.

Nevertheless, STEP is also based on the view that the perspectives are dependent and generally need to be integrated to obtain sustainable practices. In the illustrating case, the developed SD framework concerns SD as process, but it also holds that a sustainable planning process must include all the main knowledge of the socio-ecological system at hand, and, that the participatory process must be related and adjusted to its surrounding decision-making system. STEP also provides support for structuring studies of relationships between process and substance- does a planning process that fulfils SD principles of a processual character for instance always lead to decisions or plans that meet the SD principles of a substantive character? If not-does that indicate that fundamental SD principles are not included in STEP? Or, that included principles need to be reformulated?

While STEP intends to provide support for reconciling the system and process perspectives, this is easier in theory than in practice. As Miller (2013) explains, the two perspectives include different views of the meaning of SD, of the role of researchers and knowledge, and of epistemology and objectivity. Integrating the perspectives requires processes of disciplinary integration, as discussed above.

\section{General and specific definitions of SD}

From the fundamental perspectives of SD identified by Miller (2013), it follows also that SD can be defined in both general and specific terms, and that specific definitions of SD on the local scale are dependent on the knowledge and values of those connected to that locality directly and indirectly (Chesson 2013; Davidson and Venning 2011; see also Kemp et al. 2005; Morse 2008). Furthermore, the establishment of explicit links between general and specific definitions of SD is vital part of a process for turning SD into practice (Chesson 2013; Davidson and Venning 2011). Without such links, there is an obvious risk of losing sight of fundamental SD principles in the process of defining SD in specific terms. This is closely connected to the inherently normative character of the SD concept (Jordan 2008; Leach et al. 2010).

Through STEP, definitions of SD correspond to SD frameworks of varying levels of detail. The set of fundamental and well-established SD principles is the most general definition of SD, and the only definition that is not dependent on the practice studied. The more specific the SD definition, the more dependent it is on contextual factors, and on knowledge and values of those closely connected to the practice at hand (Hemmati et al. 2002; Morse 2008). These are harvested by what are called practice-based approaches in STEP.

Having said this, STEP also aims to support making connections between contextual, local definitions of SD and the SD principles. The model acknowledges this by introducing interconnected levels of SD frameworks that provide steps between SD theory and practice. These frameworks of structured interdisciplinary knowledge are systematic and explicit ways of establishing such links and render the gap between general and specific SD definitions smaller.

The illustrating case can be used to discuss in concrete terms how these connections-steps-can be established, and the fundamental role played by the alternation of theorybased and practice-based approaches. In the case example, an SD framework (called the SPF) was developed from key SD principles related to river basin planning by means of a literature survey and synthesis, ${ }^{13}$ and by interviews with researchers, which is an example of a theory-based approach. The SPF, although general and theoretical in nature, says a lot more about what SD imply for water planning than the SD principles themselves, and SPF was used to support structured and explicit analysis of such practices in relation to SD. This generated knowledge and practical advice. The empirical studies of the case provide a basis for applying a practice-based perspective on SPF, and the question of whether all the main aspects are covered by the SPF [see Hedelin (2008c) for an elaborated discussion]. Several studies of the SPF's application in different cases would be needed, however, to provide a basis for a systematic study to test the SD framework by a practice-based approach.

If one still assesses the theory-practice gap too large, a way to narrow it further would be to develop an SD framework of a more specific character, based on the SPF. That SD framework could take the form of a general planning process

\footnotetext{
13 See Kirkevold (1996) and Cooper (1998) concerning literature reviews and how to make literature synthesis.
} 
guide including general planning recommendations and tools. Such a guide could, for example, be structured by the SPF and formulate practical advice for each theme, e.g. for the theme integration of disciplinary knowledge, the guide could present typical key knowledge for water planning processes, or ways of identifying such key knowledge, and furthermore, how knowledge integration can be achieved, such as by GIS tools, serious games, shared databases and structured group discussions. Alternatively, a guide could be structured by a number of basic components of a planning process such as mapping of planning context, drawing up a process plan, selection of participants, selection of the main values affected by the process, formulation of alternatives, evaluation of alternatives, etc. Each component could include a description of key points related to it and an outline of suitable methods and tools. A theory-based approach could be used for this purpose, or a combination of both theory- and practice-based approaches. For example, a theory-based approach could be to review and summarise current applied literature on participatory planning by utilising the SPF as a structuring tool for the review. To combine that with a practice-based approach, the planning guide could be developed in as a stepwise process with alternation between literature review and planner's workshops. The SPF would be used to provide structure and theory basis for the process.

To continue to render the distance to practice smaller, the next step could be to develop a framework for action (an SD framework at a very specific level) such as a handbook or a process plan for specific actors in a specific context. For doing that, the SPF, or the more specific SD framework based on the SPF (such as a planning guide), could be used as a theoretical baseline and structure for a transdisciplinary research process that directly combines theory-based and practice-based approaches. If the intention would be to generate a plan for a specific process such as the development of a reginal river basin plan, the work could start by identifying the most affected actors of the process. A group of persons that could represent these actors could then be directly engaged to develop the process plan together with the responsible authorities and researchers. The process plan would contain issues of communication (data management, knowledge/information acquisition need for a webbased portal? meeting documentation, etc.), identification and handling of the main uncertainties, relationship to other decisions and plans, time plan, number of meetings, ways of making decisions, methods for learning and knowledge integration, ways of handling conflicts, ways of handling changes to the process, etc. The process plan could be remitted to the larger group of affected persons to incorporate their knowledge and to increase legitimacy for the planning process. During and after the resulting planning process, the SPF could be used to evaluate and learn from the process. Besides providing a theory-based case study for research, the evaluation could be used directly to adjust the ongoing planning process.

Establishment of SD frameworks and ensuring the necessary connections between these steps requires an array of methodological approaches. STEP does currently not include practical guidance for carrying out such studies. Which research methods exist at different levels of specification, for example, to ensure that the SD frameworks work as intended to link theoretical and practical levels? Even though inter- and transdisciplinary research has shown to be difficult to achieve in practice (Bammer 2015), knowledge of such methods do exist, for instance in fields as action research, transition management and transdisciplinary research (Fam et al. 2016; Lang et al. 2012; Loorbach and Rotmans 2010). A growing amount of literature from these and other fields presents practical tools for how researchers and practitioners can work together to accomplish science-based solutions to real world problems, which is key for constructing SD frameworks of specific and applied character. One example of such a tool is the framework for co-production developed by Enengel et al. (2012, p. 108) that can help identify what types of actors that may contribute with what kind of knowledge in different research phases. Another example is various participatory modelling approaches, such as conceptual modelling, cognitive mapping, and agent-based modelling, where researchers and other stakeholders engage in modelling processes to explore and manage complex socio-environmental systems. See e.g. Badham (2010) for an overview of such modelling tools. They can be used to generate knowledge about a particular system, to explore the knowledge, values, mental models and even cultural models of key stakeholders, and to support learning. I wonder if STEP has a role to play in structuring the knowledge and application of these kinds of research tools.

\section{The next step}

This then is the research model STEP. The main merits of the model are its potential to provide structural support for scientific management of SD complexity, and its operational character. Hopefully, STEP can be useful in describing, communicating and supporting the progress of ongoing research endeavours in respect of turning SD into practice, and, for supporting the design new research endeavours. STEP could also be used as a basis for structuring analysis of research in the various SD fields and for designing research agendas and large research programmes. As discussed, the interdisciplinary, open research approach that STEP aims to support is, however, often difficult to achieve in practice (Bammer 2015). Research traditions, organisational issues, politics and funding issues can make an open research approach hard to apply (Schoolman et al. 2012). Nevertheless, prevailing trends are pointing in the right direction and changes can 
occur quickly once the groundwork is prepared. I believe that STEP can make a contribution to such a change.

Utilisation of STEP will also help to produce knowledge about STEP's function and further development. The model should be regarded as a skeleton that needs to be fleshed out, specified, examined and debated in forthcoming academic work. A number of questions that such work can focus on have been raised in the discussion.

Through this paper, I hope to inspire a critical and constructive discussion of how complex SD problems can be scientifically managed in our strive to contribute to SD, and with this in mind I invite you to take part in the utilisation and further discussion and development of the modelSTEP's next step.

Acknowledgements Many dear colleagues and friends have enriched my thinking around STEP and have improved this paper with their wise comments and interesting discussions. Special thanks go to Gabriele Bammer, Birgitta Hedelin, Mikael Karlsson, Bengt Månsson, Pia Skoglund, Han Somsen and Line Säll. I also want to thank the two anonymous reviewers whose reading improved this text considerably. The work has been supported financially by the Centre of Natural Hazards and Disaster Science, a national strategic research area funded by the Swedish Government and by Formas, the Swedish Research Council for sustainable development (project number 2016-01432).

Open Access This article is distributed under the terms of the Creative Commons Attribution 4.0 International License (http://creativeco mmons.org/licenses/by/4.0/), which permits unrestricted use, distribution, and reproduction in any medium, provided you give appropriate credit to the original author(s) and the source, provide a link to the Creative Commons license, and indicate if changes were made.

\section{References}

Adam-Bradford A (2009) Integrated watershed management: connecting people to their land and water. Land Degrad Dev 20:673

Ananda J, Proctor W (2013) Collaborative approaches to water management and planning: an institutional perspective. Ecol Econ 86:97-106. https://doi.org/10.1016/j.ecolecon.2012.10.018

Badham J (2010) A compendium of modelling techniques. Integration Insights 12, May. Full text online at: https://i2sconference. net/wp-content/uploads/2014/02/integration-insight_12.pdf. Accessed 17 Sep 2018

Bagheri A, Hjorth P (2007) Planning for sustainable development: a paradigm shift towards a process-based approach. Sustain Dev 15:83-96

Bammer G (2013a) Scoping public health problems. In: Guest C, Ricciardi W, Kawachi I, Lang I (eds) Oxford handbook of public health practice, 3rd edn edn. Oxford University Press, United Kingdom, pp 2-10

Bammer G (2013b) Disciplining interdisciplinarity: integration and implementation sciences for researching complex real-world problems. ANU E Press, Canberra

Bammer G (2015) Interdisciplinarity: less vague please. Nature. https ://doi.org/10.1038/526506c

Bellamy JA, McDonald GT, Syme GJ, Butterworth JE (1999) Evaluating integrated resource management. Soc Nat Res 12:337-353
Born SM, Sonzogni WC (1995) Integrated environmental-management: strengthening the conceptualization. Environ Manag 19:167-181. https://doi.org/10.1007/bf02471988

Carpenter SR, Mooney HA, Agard J, Capistrano D, DeFries RS, Diaz $S$ et al (2009) Science for managing ecosystem services: beyond the millennium ecosystem assessment. Proc Natl Acad Sci USA 106:1305-1312. https://doi.org/10.1073/pnas.0808772106

Chesson J (2013) Sustainable development: connecting practice with theory. J Environ Assess Policy Manag. https://doi.org/10.1142/ s1464333213500026

Cooper HM (1998) Synthesizing research: a guide for literature reviews. SAGE Publications Inc, Thousand Oaks

Costanza R, Daly H, Folke C, Hawken P, Holling CS, McMichael AJ et al (2000) Managing our environmental portfolio. Bioscience 50:149-155

Daly HE (1990) Toward some operational principles of sustainable development. Ecol Econ 2:1-6. https://doi.org/10.1016/09218009(90)90010-R

Davidson KM, Venning J (2011) Sustainability decision-making frameworks and the application of systems thinking: an urban context. Local Environ 16:213-228. https://doi.org/10.1080/13549 839.2011.565464

de Sadeleer N (2002) Environmental principles: from political slogans to legal rules. Oxford University Press, Oxford

DeFries R, Nagendra H (2017) Ecosystem management as a wicked problem. Science 356:265. https://doi.org/10.1126/science.aal19 50

Dobson A (2007) Environmental citizenship: towards sustainable development. Sust Dev 15(5):276-285. https://doi.org/10.1002/ sd.344

Dryzek JS (2013) The politics of the earth: Environmental discourses. Oxford University Press, Oxford

Eckersly R (2004) The green state. Rethinking Democracy and Sovereignty. MIT Press

Ekins P (1993) 'Limits to growth' and 'sustainable development': grappling with ecological realities. Ecol Econ 8:269-288. https://doi. org/10.1016/0921-8009(93)90062-b

Ekins P, Simon S, Deutsch L, Folke C, De Groot R (2003) A framework for the practical application of the concepts of critical natural capital and strong sustainability. Ecol Econ 44:165-185. https:// doi.org/10.1016/s0921-8009(02)00272-0

Enengel B, Muhar A, Penker M, Freyer B, Drlik S, Ritter F (2012) Co-production of knowledge in transdisciplinary doctoral theses on landscape development-an analysis of actor roles and knowledge types in different research phases. Landsc Urban Plan 105(1-2):106-117

EU (2000) Directive 2000/60/EC of the European Parliament and of the Council of 23 October 2000 establishing a framework for Community action in the field of water policy. Official Journal of the European Union

EU (2007) Directive 2007/60/EC of the European Parliament and of the Council of 23 October 2007 on the assessment and management of flood risks. Official Journal of the European Union

Fam D, Palmer J, Riedy C, Mitchell C (2016) Transdisciplinary research and practice for sustainability outcomes. Routledge, Oxford

Fink A (2005) Conducting research literature reviews from papers to the Internet, 2nd edn. Sage Publications, Thousand Oaks

Folke C (2006) Resilience: the emergence of a perspective for socialecological systems analyses. Globel Environ Change 16:253267. https://doi.org/10.1016/j.gloenvcha.2006.04.002

Frame B, O'Connor M (2011) Review: integrating valuation and deliberation: the purposes of sustainability assessment. Environ Sci Policy 14:1-10. https://doi.org/10.1016/j.envsci.2010.10.009 
Gadlin H, Jessar K (2002) Preempting discord: pre-nuptial agreements for scientists. The NIH catalyst, May-June 2002. Full text online at: https://www.teamsciencetoolkit.cancer.gov/public/TSRes ourceTool.aspx?tid=1\&rid=53 Accessed 17 Sep 2018

Genus A (2014) Governing sustainability: a discourse-institutional approach. Sustainability 6:283-305. https://doi.org/10.3390/ su6010283

Grote JR (2002) Participatory governance: political and societal implications. Leske Budrich, Opladen

Grunwald A, Rösch C (2011) Sustainability assessment of energy technologies: towards an integrative framework. Energy Sustain Soc 1:1-10. https://doi.org/10.1186/2192-0567-1-3

Hammer M, Balfors B, Mörtberg U, Petersson M, Quin A (2011) Governance of water resources in the phase of change: a case study of the implementation of the EU water framework directive in Sweden. Ambio 40:210-220. https://doi.org/10.1007/s1328 0-010-0132-2

Healey P (1996) The communicative turn in planning theory and its implications for spatial strategy formation. Environ Plan B 23:217-234. https://doi.org/10.1068/b230217

Hedelin B (2007) Criteria for the assessment of sustainable water management. Environ Manag 39:151-163. https://doi.org/10.1007/ s00267-004-0387-0

Hedelin B (2008a) Criteria for the assessment of processes for sustainable river basin management and their congruence with the EU water framework directive. Eur Environ 18:228-242. https://doi. org/10.1002/eet.481

Hedelin B (2008b) Planning for sustainable use of water (Doctoral Thesis). Karlstad University, Karlstad

Hedelin B (2008c) Criteria for the assessment of planning processes for sustainable river basin management-illustration by two cases: the EU water framework directive and ongoing water planning processes in Sweden. In: Wostl CP, Kabat P, Moltgen J (eds) Adaptive and integrated water management: coping with complexity and uncertainty. Springer, Berlin, pp 405-422

Hedelin B (2015a) Further development of a sustainable procedure framework for strategic natural resources and disaster risk management. J Nat Res Policy Res 7:247-266. https://doi. org/10.1080/19390459.2015.1015815

Hedelin B (2015b) The EU floods directive in Sweden: opportunities for integrated and participatory flood risk plan. J Flood Risk Manag. https://doi.org/10.1111/jfr3.12162

Hedelin B (2016) The sustainable procedure framework for disaster risk management: illustrated by the case of the EU floods directive in Sweden. Int J Disaster Risk Sci 7:151-162. https://doi. org/10.1007/s13753-016-0093-6

Hedelin B, Lindh M (2008) Implementing the EU water framework directive-prospects for sustainable water planning in Sweden. Eur Environ 18:327-344. 10.1002/eet.489

Hemmati M, Dodds F, Enayati J, McHarry J (2002) Multi-stakeholder processes for governance and sustainability: beyond deadlock and conflict. Earthscan, London

Holling CS (2001) Understanding the complexity of economic, ecological, and social systems. Ecosystems 4:390-405. https://doi. org/10.1007/s10021-001-0101-5

Hovik S, Hanssen GS (2016) Implementing the EU water framework directive in Norway: bridging the gap between water management networks and elected councils? J Environ Plan Policy Manag. https://doi.org/10.1080/1523908x.2016.1149049

Jabareen Y (2008) A new conceptual framework for sustainable development. Environ Dev Sustain 10:179

Jager NW, Challies E, Kochskämper E, Newig J, Benson D, Blackstock K et al (2016) Transforming European water governance? Participation and river basin management under the EU water framework directive in 13 member states. Water 8:156-178. https ://doi.org/10.3390/w8040156
Jahn T, Bergmann M, Keil F (2012) Transdisciplinarity: between mainstreaming and marginalization. Ecol Econ 79:1-10. https://doi. org/10.1016/j.ecolecon.2012.04.017

Jepson EJ Jr (2001) Sustainability and planning: diverse concepts and close associations. J Plan Lit 15:499-510. https://doi. org/10.1177/08854120122093159

Jerneck A, Olsson L, Ness B, Anderberg S, Baier M, Clark E et al (2011) Structuring sustainability science. Sustain Sci 6:69-82. https://doi.org/10.1007/s11625-010-0117-x

Jordan A (2008) The governance of sustainable development: taking stock and looking forwards. Environ Plan C: Gov Policy 26:17-33

Wezemael JV, Hillier J, Roo Gd (2012) Complexity and Planning: Systems. Assemblages and Simulations, Routledge, Farnham

Karlsson M (2005) Managing complex environmental risks for sustainable development: Policies for hazardous chemicals and genetically modified organisms. (Doctoral Thesis). Karlstad University, Karlstad

Kemp R, Parto S, Gibson RB (2005) Governance for sustainable development: moving from theory to practice. Int J Sustain Dev 8:12-30

Kirkevold M (1996) Review articles-a way to strengthen the integration of nursing research. In: Bjerkreim T, Mathisen J, Nord R (eds) Vision, knowledge and work. Oslo University Press, Oslo

Koehler B, Koontz TM (2008) Citizen participation in collaborative watershed partnerships. Environ Manag 41:143-154. https://doi. org/10.1007/s00267-007-9040-z

Kopfmuller J, Lehn H, Nuissl H, Krellenberg K, Heinrichs D (2009) Sustainable development of megacities: an integrative research approach for the case of Santiago metropolitan region. Die Erde 140:417-448

Lane MB (2003) Participation, decentralization, and civil society: indigenous rights and democracy in environmental planning. J Plan Educ Res 22:360-373. https://doi.org/10.1177/0739456x03 022004003

Lang DJ, Wiek A, Bergmann M, Stauffacher M, Martens P, Moll P et al (2012) Transdisciplinary research in sustainability science: practice, principles, and challenges. Sustain Sci 7:25-43. https ://doi.org/10.1007/s11625-011-0149-x

Lange P, Driessen PPJ, Sauer A, Bornemann B, Burger P (2013) Governing towards sustainability - conceptualizing modes of governance. J Environ Plan Policy Manag 15:403-425

Leach WD, Pelkey NW (2001) Making watershed partnerships work: a review of the empirical literature. J Water Res Plan Manag 127:378-385

Leach M, Scoones I, Stirling A (2010) Dynamic sustainabilities: technology, environment, social justice. Earthscan, London

Loorbach D, Rotmans J (2010) The practice of transition management: examples and lessons from four distinct cases. Futures 42:237246. https://doi.org/10.1016/j.futures.2009.11.009

Luederitz C, Schäpke N, Wiek A, Lang DJ, Bergmann M, Bos JJ et al (2016) Learning through evaluation-a tentative evaluative scheme for sustainability transition experiments. J Clean Prod. https://doi.org/10.1016/j.jclepro.2016.09.005

Lundqvist LJ (2004) Integrating Swedish water resource management: a multi-level governance trilemma. Local Environ 9:413-424. https://doi.org/10.1080/1354983042000255324

Margerum RD (1999) Integrated environmental management: the foundations for successful practice. Environ Manag 24:151-166. https ://doi.org/10.1007/s002679900223

McMichael AJ, Butler CD, Folke C (2003) New visions for addressing sustainability. Science 302:1919-1920. https://doi.org/10.1126/ science. 1090001

Mebratu D (1998) Sustainability and sustainable development: historical and conceptual review. Environ Impact Assess Rev 18:493520. https://doi.org/10.1016/s0195-9255(98)00019-5 
Meisch S (2016) Fair distribution in the Anthropocene: towards a normative conception of sustainable development. In: Pattberg $\mathrm{P}$, Zelli F (eds) Environmental politics and governance in the Anthropocene: institutions and legitimacy in a complex world. Routledge, Abingdon, pp 62-78

Meuleman L, T Veld RJ (2010) Sustainable development and the governance of long-term decisions. Knowledge democracy: consequences for science, politics, and media. Springer, Berlin, pp $255-281$

Miller TR (2013) Constructing sustainability science: emerging perspectives and research trajectories. Sustain Sci 8:279-293

Miller TR, Wiek A, Sarewitz D, Robinson J, Olsson L, Kriebel D et al (2014) The future of sustainability science: a solutions-oriented research agenda. Sustain Sci 9:239-246. https://doi.org/10.1007/ s11625-013-0224-6

Morse S (2008) Post-sustainable development. Sustain Dev 16:341-352

Nevens F, Frantzeskaki N, Gorissen L, Loorbach D (2013) Urban transition labs: co-creating transformative action for sustainable cities. J Clean Prod 50:111-122. https://doi.org/10.1016/j.jclep ro.2012.12.001

O'Leary R, Vij N (2012) Collaborative public management: where have we been and where are we going? Am Rev Public Adm 42:507-522. https://doi.org/10.1177/0275074012445780

O'Riordan T, Jordan A (1995) The precautionary principle in contemporary environmental politics. Environ Values 4:191-212

Pezzoli K (1997) Sustainable development: a transdisciplinary overview of the literature. J Environ Plan Manag 40:549-574

Prager K (2010) Local and regional partnerships in natural resource management: the challenge of bridging institutional levels. Environ Manag 46:711-724. https://doi.org/10.1007/s0026 7-010-9560-9

Preston HJBJ (2009) Sustainable development law in the courts: the polluter pays principle. Environ Plan Law J 26:257-266

Rao PK (1999) Sustainable development: economics and policy. Blackwell, Malden

Rashman L, Withers E, Hartley J (2009) Organizational learning and knowledge in public service organizations: a systematic review of the literature. Int J Manag Rev 11:463-494. https://doi.org/1 $0.1111 / \mathrm{j} .1468-2370.2009 .00257 . \mathrm{x}$

Renn O (2009) Precaution and the governance of risk. In: Adger WN, Jordan A (eds) Governing Sustainability. Caimbridge University Press, pp 226-258

Robinson J (2004) Squaring the circle? Some thoughts on the idea of sustainable development. Ecol Econ 48:369-384. https://doi. org/10.1016/j.ecolecon.2003.10.017

Rockström J, Steffen W, Noone K, Persson A, Chapin FS, Lambin EF et al (2009) A safe operating space for humanity. Nature 461:472-475. https://doi.org/10.1038/461472a

Rosch C, Brautigam KR, Kopfmuller J, Stelzer V, Lichtner P (2017) Indicator system for the sustainability assessment of the German energy system and its transition. Energy Sustain Soc 7:13. https ://doi.org/10.1186/s13705-016-0103-y
Rotmans J, Loorbach D (2009) Complexity and transition management. J Ind Ecol 13:184-196. https://doi.org/10.111 1/j.1530-9290.2009.00116.x

Scheffer M, Carpenter S, Foley JA, Folke C, Walker B (2001) Catastrophic shifts in ecosystems. Nature 413:591-596. https://doi. org/10.1038/35098000

Schoolman ED, Guest JS, Bush KF, Bell AR (2012) How interdisciplinary is sustainability research? Analyzing the structure of an emerging scientific field. Sustain Sci 7:67-80. https://doi. org/10.1007/s11625-011-0139-z

Sneddon C, Harris L, Dimitrov R, Ozesmi U (2002) Contested waters: conflict, scale, and sustainability in aquatic socioecological systems. Soc Nat Res 15:663-675. https://doi.org/10.1080/08941 920290069272

Sneddon C, Howarth RB, Norgaard RB (2006) Sustainable development in a post-Brundtland world. Ecol Econ 57:253-268

Söderbaum P (2008) Understanding sustainability economics: towards pluralism in economics. Earthscan, London

Steffen W, Richardson K, Rockström J, Cornell SE, Fetzer I, Bennett EM et al (2015) Planetary boundaries: guiding human development on a changing planet. Science. https://doi.org/10.1126/scien ce. 1259855

Susskind L, Camacho AE, Schenk T (2012) A critical assessment of collaborative adaptive management in practice. J Appl Ecol 49:47-51. https://doi.org/10.1111/j.1365-2664.2011.02070.x

van Kerkhoff L (2014) Developing integrative research for sustainability science through a complexity principles-based approach. Sustain Sci 9:143-155

Vári A (2004) Hungarian experiences with public participation in water management. Water Int 29(3):329-337. https://doi. org/10.1080/02508060408691787

Vinet F (2008) From hazard reduction to integrated risk management: toward adaptive flood prevention in Europe. In: Proverbs D, Brebbia CA, PenningRowsell E (eds) Flood recovery, innovation and response. Springer, Japan, pp 113-122

Wagner W, Gawel J, Furumai H, De Souza MP, Teixeira D, Rios L et al (2002) Sustainable watershed management: an international multi-watershed case study. Ambio 31:2-13

Walker G (2009) Globalizing environmental justice: the geography and politics of frame contextualization and evolution. Global Soc Policy 9:355-382. https://doi.org/10.1177/1468018109343640

Walker G (2012) Environmental justice: Concepts, evidence and politics. Routledge, Abingdon

WCED (1987) Our common future. Oxford University Press, Oxford

Weiss J, Hughes J (2005) Want collaboration? Accept-and actively manage-conflict. Harv Bus Rev 83:92-101

Wiek A, Ness B, Schweizer-Ries P, Brand FS, Farioli F (2012) From complex systems analysis to transformational change: a comparative appraisal of sustainability science projects. Sustain Sci 7:5-24. https://doi.org/10.1007/s11625-011-0148-y 